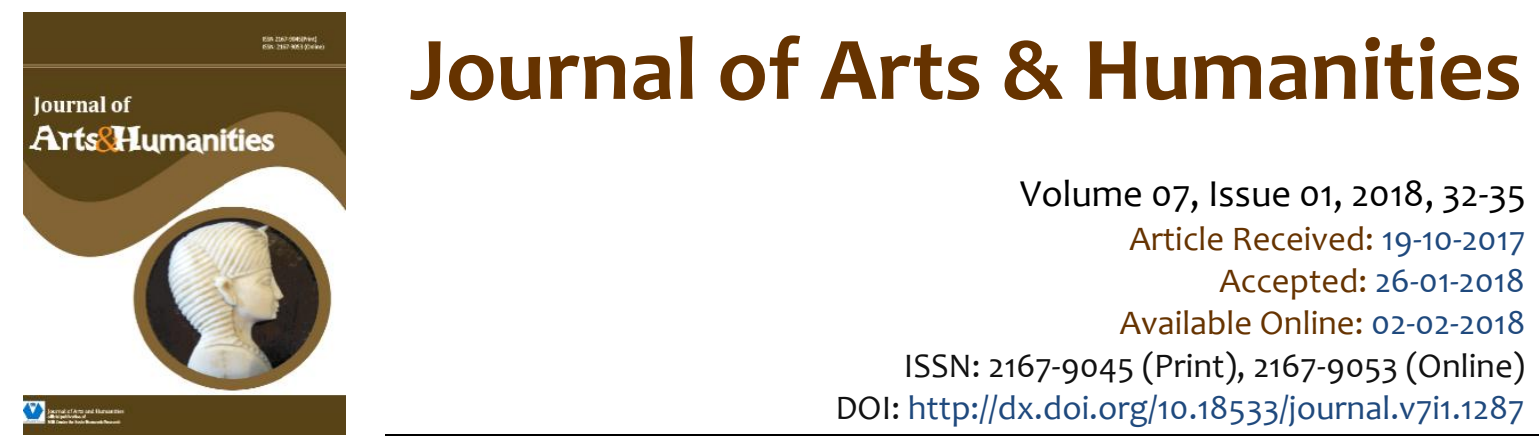

\title{
The Influence of Art Symbol of Ming Dynasty furniture on Contemporary Home Furnishing
}

\author{
Zhao Wei', RongRong Xu'
}

\begin{abstract}
Nowadays, Chinese style is a hot topic. On the application of Chinese style in home design, Ming Dynasty furniture is indeed a classic in the history of ancient Chinese furniture, it reveals the excellent thoughts of Chinese culture, this symbol thought contribute to the Chinese style toward the international. The Art symbolic throughout penetrate the home design. Symbolic thought in various stages of the design is only slightly different form of expression, its connotation is the first design philosophy of China. The design of furniture in the Ming Dynasty has been affecting modern home design. We have to carefully study the background of the furniture design of the Ming Dynasty, and finally summarize the main points of the generation of furniture design.
\end{abstract}

Keywords: Artistic Symbolization, Chinese Style, Ming Dynasty Furniture, Modern Home Design.

This is an open access article under Creative Commons Attribution 4.0 License.

"China style" is a hot topic of people at the moment, different periods of Chinese style endowed with different connotations. The design from all walks of life has taken on a new look due to the rise of the Chinese style. In terms of the application of Chinese style in home design, I would like to talk about the art of furniture in Ming dynasty. Ming furniture is indeed a classic in the history of ancient Chinese furniture. It is also unique in the world furniture history.

In the process of globalization, nationality actually is the key to cultural heritage. While focusing on internationalization, we turn our attention to the traditional culture. Reviewing the classic furniture of the Ming Dynasty, all of them reveal the excellent thought of Chinese culture, the symbolic thought contribute to the Chinese style move towards the world.

The chair is in the Han Dynasty from the North into Central Plains "Huchuang" evolved. Rose chair, round-backed armchair, an ancient folding chair of the appear time is different, but they were all development mature in the Ming Dynasty. The symmetry and balance of the furniture symbols in Ming Dynasty are the concentrated expression of Confucian "Neutralization" thought. Through the picture, we can see intuitively, the overall shape of the chair is axial symmetry, federal stick embody the

\footnotetext{
1 Shanghai University of Engineering Science, College of Fashion Design.

2 Shanghai University of Engineering Science, E -mail: 455119220@qq.com
} 
Confucian thought of "middle" in between back and goose neck, locally decorated axle wire and composition ;secondly, take the chair plate as the boundary, the upper and lower parts of the spatial equilibrium and carved parts by ordered arrangement. And a combination of straight lines and so on all embody the thought of "harmony" in Confucianism.

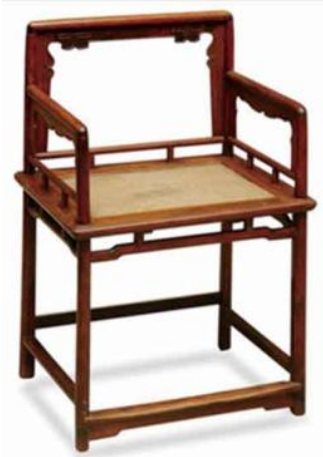

Figure 1: Rose chair

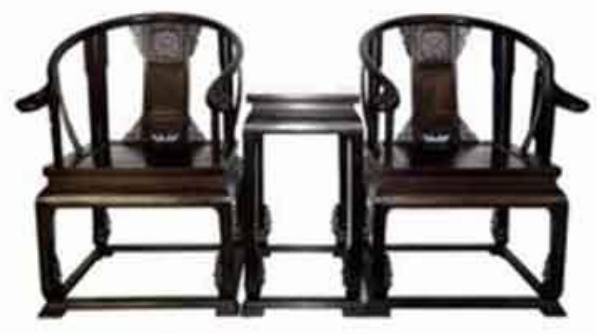

Figure 2: Round-backed armchair

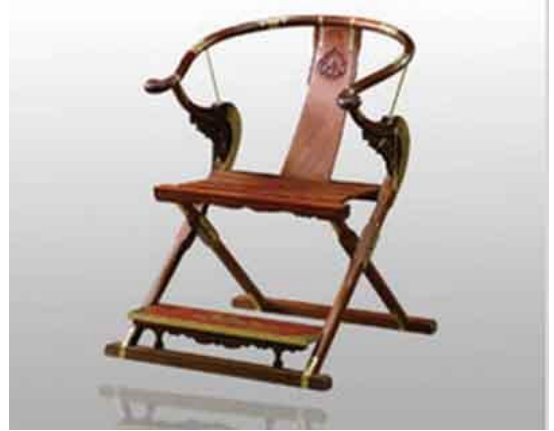

Figure 3: An ancient folding chair

Mandarin chair in Ming dynasty chairs furniture symbol is the classic styling. BBK catch Cheng and auspicious decorative patterns are reflected in the Confucian thought of "go into the world". As shown in the figure, the other looks like ancient officials hat to the name. Over four armchairs and headband form is similar, move the view to the side of the chair, armrest is like the front of the hat ,morphology characteristics of Mandarin chair has the overall shape, It embodies the Confucian "go into the world" of philosophy, to be more clear in the BBK catch Cheng symbol "be promoted step by step "in the pursuit of life. Throughout the Ming Dynasty furniture, many decorative patterns can reflect people's pursuit of wealth, peace, harmony and rights, but also reflects the people's "go into the world" attitude.

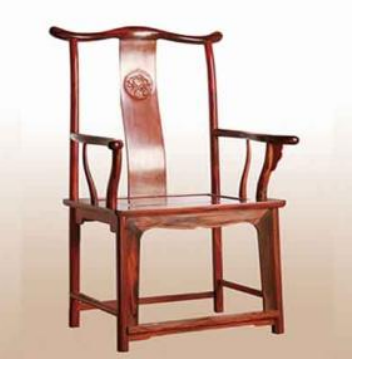

Figure 4: Mandarin chair

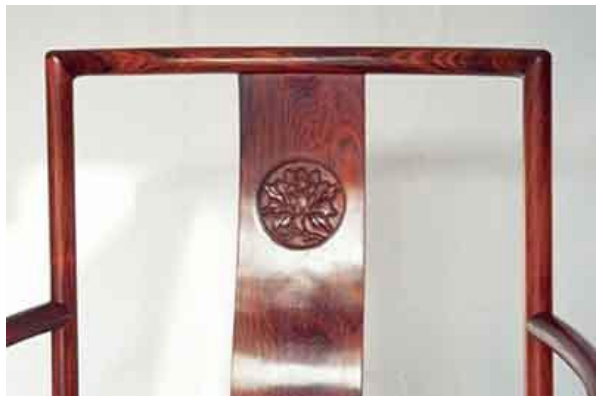

Figure 5: Backboard pattern

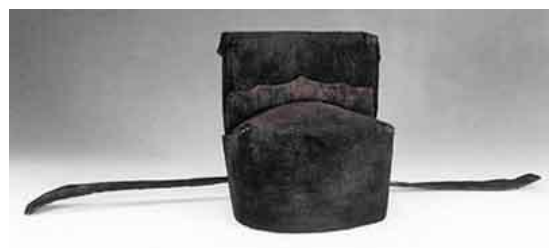

Figure 6: Catch Cheng

Ming Dynasty chairs a lot of places follow the "furniture etiquette."". In the Ming Dynasty, there were strict code of ethics for sitting posture, such as back straight, shoulders relaxed, female knees close together, man's knees separated slightly, no more than shoulders, hands are naturally placed on the arm of the knee or chair. The Ming Dynasty seated position stress dignified and beautiful, elegant and stable, meanwhile revealing the philosophical thought of "sit square". This kind of symbol thought makes the furniture structure of the Ming Dynasty chair mostly linear, and gives people the sense of being upright, and gives people a sedate and generous. The design form is straight and tough, sleepy or small break are required to fit the desk, particularly dignified, fit together elegant temperament of the people. "vertical worship" and "good sitting posture" became the social fashion at that time, and this kind of sign behavior is ingeniously reflected in the furniture.

Throughout the Ming Dynasty furniture development, its unique charm circulate far and wide. First of all, literati involved in the design, very beautiful craftsman. Secondly, the choice of materials is investigate,

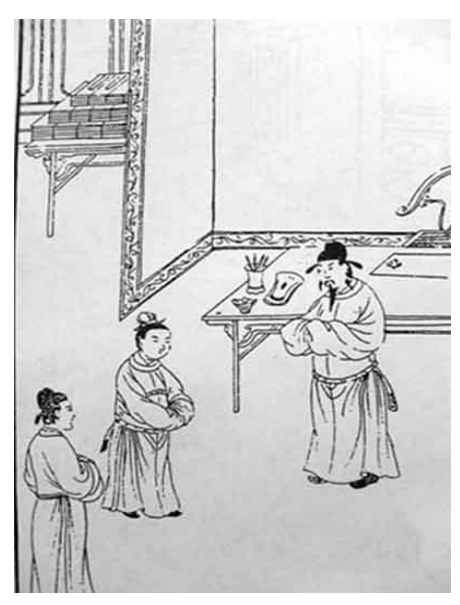

Figure 7: Yangzheng graphic: Chong ask method 
showing the beauty of nature. Finally, a simple and reasonable structure, firm connection, very beautiful exquisite. They are five characters: ancient, elegant, refined, beautiful and simple. Until today, the artistic symbol of the Ming Dynasty furniture still influences the contemporary home design, so the Chinese style has a changeable style in the house design.

Hereon, I think there are two points that influence the Ming Dynasty furniture so far. The first point is the art symbol in Ming Dynasty furniture. Second: simple. Put Visual angle in contemporary home design, both are fully reflected. With the development of society and the improvement of living standard, people's concept of life is changing gradually. The standards of food and clothing were far from meeting the demands of modern people, desire and

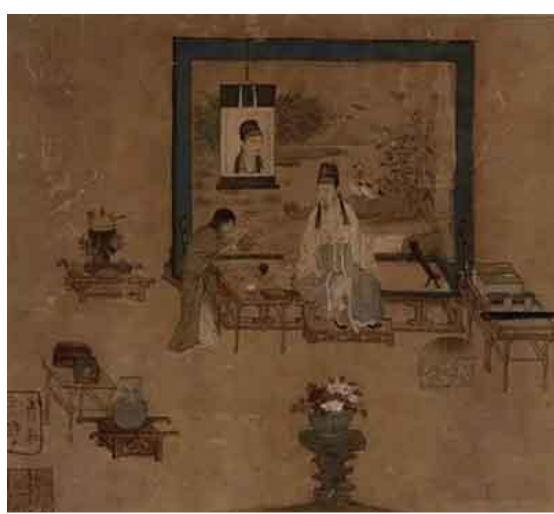

Figure 8: Qiu Ying (copy Song Dynasty album) thought were advancing. Beauty is the product of the development of the times, and the perceptual prominence of people's ideas. Manage our life with our heart and modern design will be more exciting. In the contemporary home design, the concept and works of several excellent designers make us light.

In 2006, Mr. Lv Yongzhong founded the half wooden original furniture brand, advocating the life style and life aesthetics of contemporary china. In 2000, everybody began to know his "sweet flute" aroma design. Over ten years, he created a design" seal character "chair," Plece of boat" stool," Huizhou "executive desk ," Suzhou "chair," cool breeze"Zen bed," rose wood drum leg care mud arhat bed "many other pieces of classical Home Furnishing design works, many times invited the international exhibition and auction.

"Half wood," most of the products are wood materials, founder Mr. Lv Yongzhong explained: "wood is only one of the materials I choose, does not mean that everything i want to do in the future is wood." In his view, "wood" is actually something more Oriental, while western stony things. This is also true in our view. In the ancient furniture of our country, wood material has always been the main material. The ancient China designer known as the "artisan", used to make furniture made of wood. This custom has been origin circulation down and created an impression on our character. We instinct have a sense of kind with wooden furniture, so the wood itself is an art symbol, and it is a design in the Chinese sense.

As the saying goes: "Setting sunshine of west lake". This aroma design uses the traditional mortise and tenon structure of China, which can be used to realize the fun of hands -on assembling and disassembling. Mortise and tenon symbols are usually used to connect components. Most furniture in Ming Dynasty was connected by mortise and tenon structure. This symbol has long been popular among people. The art symbol is still common in contemporary Home Furnishing design, and will not fade because of the time span, visible on the current deep influence of Ming Dynasty.

Chinese American product designer Shi Dayu since 2007 began to try cross-border design, the original brand of the Qing court to the market. The designer has a special liking for bamboo materials, starting with
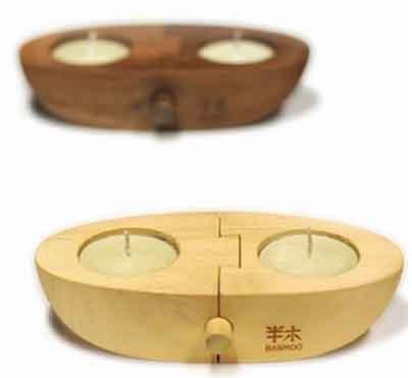

Figure 9: bamboo materials to designing household products and studying Chinese traditional culture. Under the leadership of Mr. Shi Dayu, the design idea of the Qing court team that is will be rooted in the great wisdom of Chines traditional folk arts and crafts, and integrate into the present life, combining modern western design, reinventing contemporary home design. "Harmony between man and nature" of design philosophy embodied in Shi Dayu's products. This symbolic thought was also manifested in the furniture of Ming dynasty. "Harmony between man and nature" is the core of Chinese ancient philosophy. As early as Zhou Dynasty, <Qian Yi>saying : "the great person, Unite with heaven and earth, and fit the sun and the moon, and fit when the four order, and fit its good and bad spirits will; but the heaven is not violated, In the day after tomorrow, the change of the Tao must also follow its laws." This remark explains the idea of harmony between man and nature, it is harmony nature, man and nature, man and man, body and mind, and inside and outside. And the harmony of furniture of Ming 
Dynasty is reflected in component flowing and concise, curve static and dynamic combination, outline is stress square, dimension scale harmony. We can see that in Shi Dayu's modern design.

2012 "Rigid and flexible chair" by the Taiwan creative Design Center awarded "Gold Award for design". Designers use the Ming Dynasty round-backed armchair for design theme, the continuation of the traditional structure of mortise and tenon, but also gives the traditional round-backed armchair to the modern soul, more suitable for modern people's way of life. It is unique in that it is a Stackable full bamboo chair, in this design, the characteristics of the Ming Dynasty furniture designers have an ulterior motive hidden "ancient, elegant, refined, beautiful and simple".

In summary, art symbol throughout the home

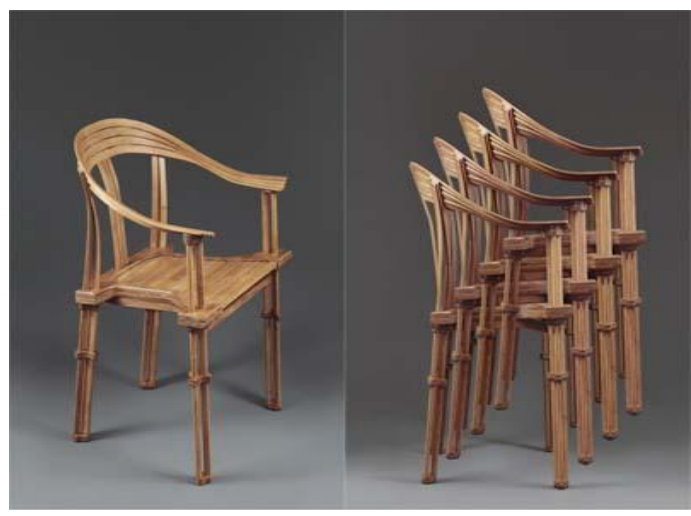

Figure 10: Rigid and flexible chair design. The symbol of traditional design in each stage just a

slightly different form of expression, it's the kernel still is the supremacy of the Chinese design philosophy. Contemporary designers note that the design career should have a sense of design responsibility and a heritage mission. When nationalism is inherited and optimized, international recognition will be higher. The so-called design test China, is not a test of our ability to design, but the quiet heart, thinking of ancient essence, and the appropriate inheritance in contemporary times. We have to inherit excellent design ideas from tradition. In the future design, we should pay attention to the heritage of culture. It is not only to highlight the fashion sense of modern furniture design, but also to inherit the essence of human culture.

\section{References}

Li De jun, Sun Weiwei, Ling Jiyao, The Analects of Ming and Qing Dynasties bamboofurniture design beauty $[J]$. Journal of bamboo research

Chen Lai, neo-confucianism [M]. Shanghai: East China Normal University press

Zhang Xianrong, design semiotics [M]. Beijing: Chemical Industry Press

Qiu Jingyuan, riverside, Ai Honghua, Chinese design aesthetics: Construction Industry Press

Wujiang, Chen Zhenyi, Ming style furniture, the beauty of the road and the modern product design inspiration [J]. Packaging engineering 